\title{
Rarely seen temporary subclavian vein spasm and twitching on the epicardial battery
}

\section{Ender görülen geçici subklavyen ven spazmı ve epikardiyal bataryada seğirme}

\author{
Derya AYDIN ŞAHIN ${ }^{1}$, Osman BAŞPINAR ${ }^{2}$
}

ABSTRACT

Complications occurring during or after the implantation of permanent pacemaker through transvenous route may have important consequences that can even change the treatment modality. One of these complications is temporary subclavian vein spasm occurring during the transvenous permanent pacemaker implantation. Another one is twitching on the pacemaker pocket. We will present two cases; one of them who has temporary subclavian vein spasm occurred during the transvenous permanent pacemaker implantation and twitching on epicardial pacemaker battery, another one has twitching on epicardial pacemaker battery.

Keywords: Transvenous pacemaker, subclavian vein spasm, twitching on epicardial pacemaker battery, child
Öz

Transvenöz kalıcı kalp pili yerleştirilmesi işlemi sırasında veya sonrasında oluşan komplikasyonlar tedavi şeklini dahi değiştirebilecek önemli sonuçlar oluşturabilir. Bu komplikasyonlardan bir tanesi transvenöz kalp pili takılması sırasında oluşan geçici subklavyen ven spazmıdır. Diğer bir komplikasyon kalp pili bataryasında olan seğirmedir. Biz transvenöz kalp pili yerleştirilmesi sırasında geçici olarak oluşan subklavyen ven spazmı ve epikardiyal kalp pili bataryasında seğirme olan bir vaka ve ayrıca epikardiyal kalıcı kalp pili olan başka bir hastada aynı şekilde kalp pili bataryasında seğirme olan diğer bir vakayı sunacağız.

Anahtar kelimeler: Transvenöz kalp pili, subklavyen ven spazmı, kalp pili bataryasında seğirme, çocuk

\section{GíRiş}

Transvenöz kalıcı kalp pili yerleştirilmesi işlemi sırasında veya sonrasında oluşan komplikasyonlar tedavi şeklini dahi değiştirebilecek sonuçlar oluşturabilir. Bu komplikasyonlardan bir tanesi transvenöz kalp pili takılması sırasında oluşan geçici subklavyen ven spazmıdır ve literatürde ender olarak bildirilmiştir. İnsidansı, risk faktörleri ve efektif tedaviyi içeren bilgiler henüz tam olarak bilinmemektedir ${ }^{1-4}$. Diğer bir komplikasyon ise kalp pili bataryasında olan seğirmedir ve yine çok ender olarak bildirilen vakalar mevcuttur ${ }^{5}$. Bu makalede transvenöz kalp pili yerleştirilmesi sonucunda geçici olarak oluşan subklavyen ven spazmı ve epikardiyal kalp pili bataryasında seğirme olan bir vaka ve ayrıca epikardiyal kalp pili olan başka bir has- tada aynı şekilde kalp pili bataryasında seğirme olan diğer bir vaka sunuldu.

\section{OLGU 1}

Altı yaşında kız hasta, dört yıl önce Fallot Tetrolojisi nedeniyle opere edilmiş, operasyon sonrasında 3. derece atriyoventriküler blok gelişmesi nedeniyle epikardiyal kalp pili takılmış. Pil ömrünün bitmesi nedeni ile epikardiyal kalp pili bataryasının çıkarılıp, transvenöz kalıcı kalp pili takılması için hasta anjioya alındı. Sol subklavyen venden ponksiyon iğnesi ile defalarca kanülasyon denenmesine rağmen, başarılı olunamayınca brakial venden kontrast madde verildi ve subklavyen vende ağır spazm olduğu görüldü (Figür 1a). 0,25-0,5 mcg/kg/dk. intravenöz yineleyen

Received: 23.12 .2015

Accepted: 04.02.2016

${ }^{1}$ Pediatric Cardiology Clinics, Suleymaniye Obstetrics And Children Training and Research Hospital

2Department Of Pediatric Cardiology, Gaziantep University

Yazışma adresi: Derya Aydın Şahin, Pediatric Cardiology Clinics, Suleymaniye Obstetrics and Children Training and Research Hospital, Istanbul

e-mail: deryaaydin01@mynet.com 
dozlarda nitrogliserin yapıldı, son dozdan sonra yaklaşık $30 \mathrm{dk}$. beklenmesine rağmen, subklavyen vende gelişen spazmda düzelme olmadı. Bunun üzerine kalp damar cerrahisi tarafından batındaki epikardiyal batarya çıkarıldı, yerine St Jude Microny pacemaker batarya implantasyonu yapıldı. Lead ölçümleri yinelendi. Bir ay sonra hasta batında sol üst lomber bölgede pil bataryasında seğirme yakınması ile başvurdu. Lead ölçümlerinde sorun olmadığı görüldü ve hasta iki hafta sonra yine kontrole çağrıldı. Hasta kontrole geldiğinde pil bataryasının olduğu bölgede halen kas seğirmesinin olduğu görüldü. Bunun nedeninin Microny pacemakerin sense polaritesinin bipolar olduğu halde pace polaritesinin unipolar olmasına bağlandı. Ayrıca subklavyen vendeki spazmın yine değerlendirilmesi için anjioya alındı ve brakiyal venden kontrast madde verildi, subklavyen ven spazmının kaybolduğu görüldü.

\section{OLGU 2}

Altı yaşında erkek hasta, 4 yaşında ventriküler septal defekt nedeniyle opere edilmiş, operasyondan sonra 3. derece atriyoventriküler blok gelişmesi üzerine epikardiyal kalıcı kalp pili takılmış. Pil kontrolü için kliniğimize başvuran hastanın batında sol periumblikal bölgeye konan pil bataryasında seğirme olduğu görüldü (Figür 1b). Pil kontrollerinde sorun olmayan hastanın pil bataryasındaki seğirmesinin nedeni de aynı şekilde Microny pacemakerin sense polaritesinin bipolar olduğu halde, pace polaritesinin unipolar olmasına bağlandı.

\section{TARTIŞMA}

Transvenöz kalp pili yerleştirilmesi işlemi sırasında bir çok komplikasyonlar görülebilir ve bu tedavi şeklini değiştirebilir. Birinci vakamızda transvenöz kalp pili yerleştirilme işlemi sırasında subklavyen ven spazmı gelişti. Yineleyen dozlarda nitrogliserin yapılmasına rağmen spazmda düzelme olmadı. Daha sonra hasta 1 ay sonra kontrole çağrıldı ve venogram yinelendi. Subklavyen vendeki spazmın düzeldiği gözlendi. Literatürde bilgilerimize göre çocuklarda subklavyen ven spazmı bildirilmemiştir, erişkinde ise vakamıza benzer
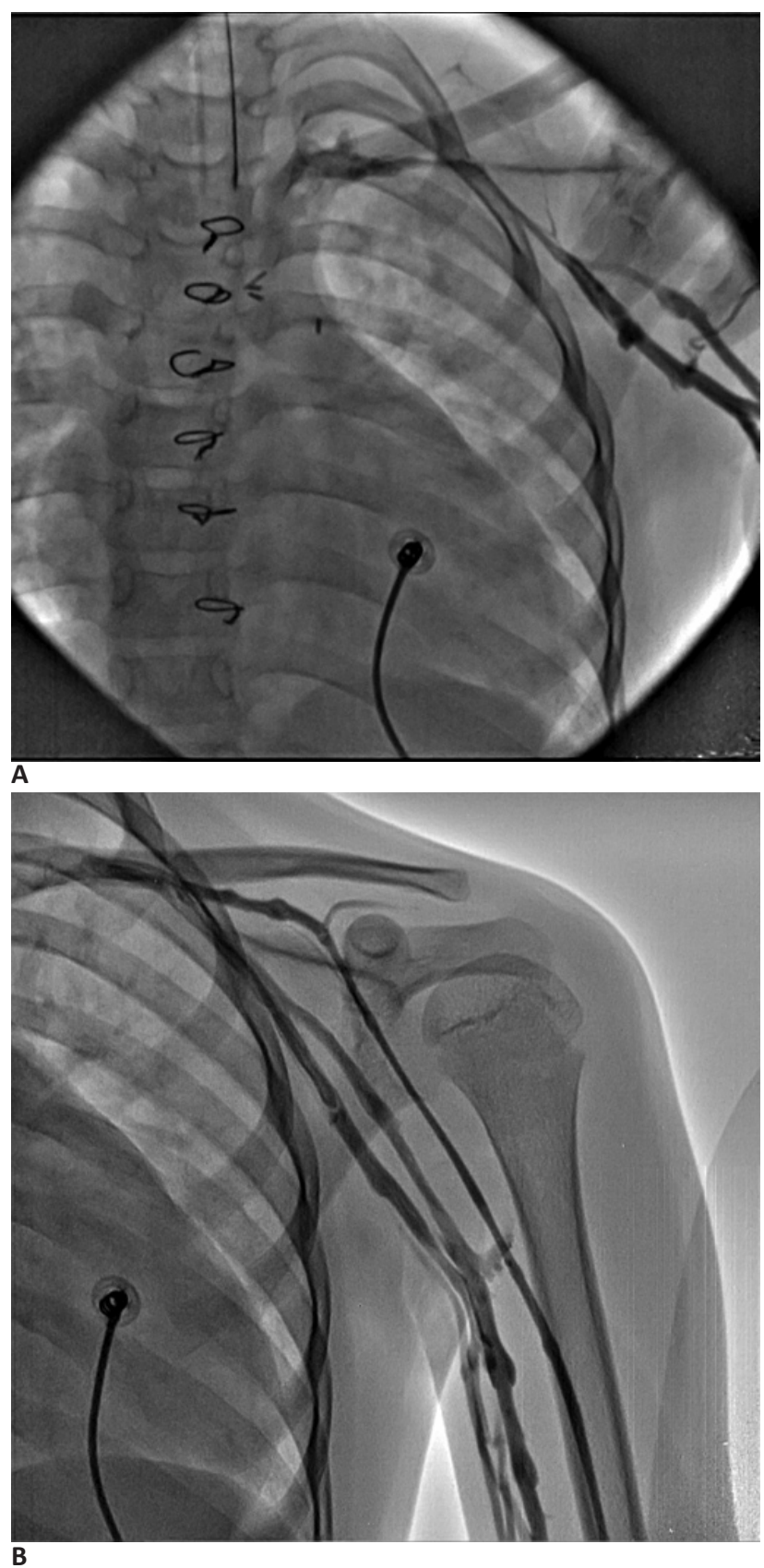

Figür 1a-b. Ender görülen geçici subklavyen ven spazmı ve epikardiyal bataryada seğirme.

şekilde vakalar bildirilmiştir. Yetmiş beş yaşında kadın bir hastaya atriyal fibrilasyon ve komplet atriyoventriküler blok nedeniyle pacemaker implantasyonu için sol subklavyen venden ponksiyon yapılmış ancak başarısız olunmuştur. Daha sonra yapılan venogramda belirgin venöz spazm görülmüş, nitrogliserin uygulanmasına da yanıt alınamayınca implantasyon yeri sağa kaydırılmış ve başarılı bir şekilde pacemaker 
implante edilmiştir ${ }^{1}$. Yetmiş dört erişkin hastayı içeren bir başka çalışmada, 6 vakada $(\% 8,1)$ ciddi venöz spazm görülmüş, 3 vakada girişim başarısız olmuştur. Bunun nedeni tam olarak açıklanamamıştır, ancak bu vakaların hepsinin yaşının 70 yaş üzerinde olduğu tespit edilmiş ve ileri yaşın risk faktörü olabileceği öne sürülmüştür².

Kardiyovasküler girişimler sırasında arter spazmları venöz spazmlara göre çok daha sık görülmektedir. Arter spazmlarının mekanizmasının miyojenik refleksi tetikleyen mekanik irritasyon, reseptör aktivasyonu ve vazoaktif ajanların salınımıyla kateter ucunda trombosit agregasyonu olduğu öne sürülmüştür6-10. Venöz spazmların mekanizması tam olarak bilinmemektedir, bazı araştırmacılar bunun kontrast maddenin kimyasal etkisi, iğne girişiminin mekanik etkisi veya kılavuz telinin yerleştirilmesiyle ilişkili olabileceğini ileri sürmüşlerdir ${ }^{2,3}$.

Ayrıca hem birinci vakamızda hem de epikardiyal kalp pili olan başka bir hastamızda da kalp pili bataryasında seğirme tespit edildi. Bunun nedeni olarak Microny pacemaker'in sense polaritesinin bipolar olduğu halde, pace polaritesinin unipolar olması düşünüldü. Bu iki hasta da seğirmeden rahatsız değildi, aile herhangi bir müdahaleyi kabul etmedi. Kalp pili de uygun olarak çalıştığı için herhangi bir müdahalede bulunulmadı. Vakalarımıza benzer olarak literatürde yalnızca erişkin bir vakaya rastladık. Bu vaka 83 yaşında erkek bir hasta idi. Hastaya Mobitz tip 2 blok nedeniyle çift odalı pacemaker takılmış, daha sonra sağ hemidiyafragmatik uyarılma olup, bunun sağ frenik sinir uyarılmasına bağlı olduğu düşünülmüştür. Pacemakerin bipolar modunun unipolar moda çevrilmesi ile seğirme düzelmiştir ${ }^{5}$.

Sonuç olarak, kalp pili yerleştirilmesi sırasında sık olarak kullanılan venöz girişim yeri olan subklavyen vende spazm ender olarak gelişebilir, genellikle ge- çici ve başarısızdır. Kardiyologlar tarafından periferik diyagnostik ve girişimsel işlemler artan oranlarda uygulandığı için multipl vasküler yataklarda kateterle ilişkili vazospazm görülmesi aşikardır, gereksiz girişimlerden kaçınmak bu olasılığı azaltır ve bu konuda farkındalık artırılmalıdı ${ }^{10}$. Kalp pili bataryasındaki seğirme ise çok ender bir komplikasyondur. Bu gibi durumlarda öncelikle lead kırı̆ı̆, kalp pili malfonksiyonu düşünülmeli, eğer bunlar saptanamazsa leadin sense ve pace polaritesinin bipolar mı unipolar mı olduğu ve uyumlu olup olmadığına dikkat edilmelidir.

\section{KAYNAKLAR}

1. Duan $\mathrm{Xu}$, Ling $\mathrm{F}$, Shen $\mathrm{Y}$, et al. Venous spasm during pacemaker implantation. Anadolu Kardiyol Derg 2011;11:E23-E25.

2. Duan $\mathrm{Xu}$, Ling F, Shen $\mathrm{Y}$, et al. Venous spasm during contrastguided axillary vein puncture for pacemaker or defibrillator lead implantation. Eurpace 2012;14:1008-1011. http://dx.doi.org/10.1093/europace/eus066

3. Chan NY, Leung WS. Venospasm in contrast venographyguided axillary vein puncture for pacemaker lead implantation. Pacing Clin Electrophysiol 2003;26:112-113. http://dx.doi.org/10.1046/j.1460-9592.2003.00161.x

4. Cooper RM, Krishnan U, Pyatt JR. Central venous spasm during pacemaker insertion. Heart 2010;96:1484. http://dx.doi.org/10.1136/hrt.2010.203919

5. Khan AA, Nash A, Ring NJ, Marshall AJ. Right hemidiaphragmatic twitching: A complication of bipolar atrial pacing. Pace 1997;20:1732-1733. http://dx.doi.org/10.1111/j.1540-8159.1997.tb03550.x

6. Osborn LA, Reynolds B. Vagally mediated multivessel coronary artery spasm during coronary angiography. Catheter Cardio Diagn 1988;44:423-426.

http://dx.doi.org/10.1002/(SICI)1097-0304(199808)44:4< 423::AID-CCD14>3.0.CO;2-J

7. Heijman J, El Gamal M, Michels R. Catheter induced spasm in aortocoronary vein grafts. Br Heart J 1983;49:30-32. http://dx.doi.org/10.1136/hrt.49.1.30

8. Dodek A, Hooper RO. Coronary spasm provoked by angiography. Am Heart J 1984;107:781-784. http://dx.doi.org/10.1016/0002-8703(84)90329-6

9. Chierchia S. Pathogenetic mechanisms of coronary vasospasm. Acta Med Scand Supp/ 1982;660:49-56. http://dx.doi.org/10.1111/j.0954-6820.1982.tb00360.x

10. Shortal BP, Mahmud E, Tsimikas S. Catheter-induced vasospasm of both the right external iliac and right coronary arteries during coronary angiography. Int J Cardiovasc Imaging 2005;21:481-485.

http://dx.doi.org/10.1007/s10554-005-2101-6 